\title{
Study on quinolone accumulation and growth inhibition induced by quinolone levels of hydroponics
}

\author{
Xiaojuan Wang ${ }^{1}$, Yaojun Wang ${ }^{1}$, Jiangwen Nian ${ }^{1}$, Yongbo Sun ${ }^{2}$, Yonghui Zhang ${ }^{3}$, Yunsheng Xia ${ }^{1}$, Fei Wang ${ }^{3}$, Lifang \\ Wang $^{3}$, Ruirui Liu ${ }^{1}$, Xiaolin Liao ${ }^{1}$, Leifeng Zhao ${ }^{1}$, Chun $\mathrm{Xia}^{3}$, and Fuzhao Nian* \\ ${ }^{1}$ Yunnan Agricultural University, Kunming 650201, Yunnan Province, China \\ ${ }^{2}$ Oriental Tobacco Co., Ltd. of Yunnan, Baoshan 678000, Yunnan Province, China \\ ${ }^{3}$ Luzhou Company of Sichuan Tobacco Company, Luzhou 646000, Sichuan Province, China
}

\begin{abstract}
Residual antibiotics can enter soil and water bodies through organic fertilizers with food safety risk via plants absorption, while how do plant growth and quinolone accumulation respond to residual antibiotics levels in soil or water is not clear. Hydroponic experiment in greenhouse was conducted with floating seedlings of tobacco as model plant to investigate the responses of quinolone antibiotics accumulation and plant growth to different levels of ciprofloxacin (CIP) and norfloxacin (NOR). Results showed that CIP and NOR inhibited the growth of tobacco seedlings. The plant height, stem circumference, maximum leaf width, and maximum leaf area of tobacco seedlings were significantly decreased. So as to the plant biomass of leaves, stems, and roots. Accumulation of CIP in the tobacco seedlings in the T3 was 1.1 times that of the tobacco seedlings in the T1, NOR in the T4 was 1.2 times that of the tobacco seedlings in the T1. And the higher the concentration, the more significant the inhibitory effect. Both antibiotics can be absorbed and accumulated by tobacco seedlings. Additionally, the inhibitory effect of CIP was greater than that of NOR.
\end{abstract}

\section{Introduction}

Antibiotics are widely used in medicine for its inhibition to microorganisms or virus, which could prevent and treat animal diseases in veterinary industry and control infection caused by bacterium and fungus in agriculture. Antibiotics can't be absorbed entirely almost all application in any field and a large portion will reside in water body, soil and organisms through ecology cycle. With increasing importance of environmental protection worldwide more and more research on antibiotic pollution detected quinolones in streams of Hubei Province of China, Fujian Province of China and Watershed in the valley of Grat, Switzerland [1]. Quinolones are widely used in humans and animals, such as ciprofloxacin and norfloxacin are two main products [2,3]. Residual antibiotics can enter soil and water bodies through organic fertilizers derived from human and animal excreta, with food safety risk via plants absorption. It was reported that there were $0.465-0.715$ $\mathrm{ug} / \mathrm{kg}$ of norfloxacin residuals in soil-vegetable systems [4], residuals of four quinolone antibiotics were detected in more than $80 \%$ vegetables grown in Dongguan, China, which highest content was more than $100 \mathrm{ug} / \mathrm{kg}$ (dry weight) [5]. Researchers conducted experiment by adding antibiotics in different combination which including CIP, NOR and tetrcycline (TET) to Chinese cabbage roots to study antibiotics toxicity, and results showed that no matter single antibiotic or antibiotics combination could inhibited the root growth of Chinese cabbage and combinations caused larger toxicity [6]. Finding a kind of plant to remediate antibiotic pollution is necessary. Tobacco, a kind of finical plant, is widely cultured in southeast area of China. There are research found that tobacco could absorb and accumulate pollutions in soil like heavy metals, which could be used to soil pollution remediation $[7,8,9]$. Therefore, tobacco was used as model crop in this research to study the responses of quinolone antibiotics accumulation and plant growth to different quinolone levels of hydroponics with tobacco seedlings, aiming at finding novel antibiotic utilization on tobacco culture and environmental remediation of antibiotic pollution. Section 2 outlines the materials and methods related to the research. Section 3 surveys our results and discussions. In Section 4 the conclusion of the research is presented.

\section{Materials and methods}

\subsection{Selected tobacco variety and antibiotics}

The experiment was carried out with a variety of fluecured tobacco and two antibiotics. Yunyan97, a new flue-cured tobacco variety, was produced by hybrid

\footnotetext{
* Corresponding author: fuzhaonian@126.com
} 
breeding of Yunyan85 and CV87 from Yunnan institute of tobacco agricultural science. In recent years, yunyan97 is one of the flue-cured tobacco varieties widely cultivated in Yunnan province. Additionally, ciprofloxacin (CIP) and norfloxacin (NOR) are two commonly used quinolones antibiotics. According to local planting practices and common standard of quinolone antibiotics, the flue-cured tobacco variety used was Yunyan97. CIP and NOR were purchased from BoMei biotechnology co., LTD., Hefei, China, with purities $\geq 99 \%$ were used.

\subsection{Experimental design}

Flue-cured tobacco were treated with 25 (T1), 50 (T2), 75 (T3), and 100 (T4) mg antibiotic/L for CIP and NOR, respectively, by adding antibiotics to distilled water. In addition, we applied one control treatment 0 (CK) (distilled water).

The experiments were performed in the solar greenhouse of Yunnan Agricultural University. Floating seedlings were used, distilled water was irregularly added, and the volume of the nutrient solution was maintained at $14 \mathrm{~L}$. Twenty days after sowing, after the tobacco seedlings had grown 4 true leaves, the antibiotic treatment was started. Samples were taken at $30 \mathrm{~d}, 40 \mathrm{~d}$, and $50 \mathrm{~d}$ after antibiotic treatment (i.e., $50 \mathrm{~d}, 60 \mathrm{~d}$, and $70 \mathrm{~d}$ after sowing). Fifteen tobacco seedlings were randomly collected for each treatment, and every five plants were repeated once. The roots, stems, and leaves were separated and weighed, and these values were taken as the fresh weights.

\subsection{Measurement indicators and methods}

The method used by Nian et al. [10] was used to determine the antibiotic contents in the seedlings and to calculate the cumulative amount of antibiotics per plant. The method outlined in the "YCT142-2010 investigation and measurement methods of tobacco agronomic traits" [11] was used to determine the agronomic traits of the tobacco seedlings 50 days after antibiotic treatment. And then, data analysis was performed with SPSS 2.0 and Microsoft Excel 2013 software.

\section{Results and Discussions}

\subsection{Responses of tobacco seedlings growth to different levels of ciprofloxacin and norfloxacin}

Plant growth indexes of height, stem circumference, and maximum leaf length, width, area, were all decreased continuously with increasing antibiotic concentration in nutrient solution (table 1). Particularly, the plant height, stem circumference, maximum leaf width, and maximum leaf area of tobacco seedlings were significantly decreased $16.9 \%, 7.5 \%, 10.4 \%$, and $13.1 \%$ by $100 \mathrm{mg} / \mathrm{L}$ CIP, and $11.3 \%, 10.1 \%, 12.6 \%$, and $16.7 \%$ by $100 \mathrm{mg} / \mathrm{L}$ NOR orderly. It indicated that the plant growth especially plant height and leaf area of tobacco seedlings were inhibited by increased antibiotic levels.

Plant biomass of leaves, stems, and roots were all decreased continuously with increasing antibiotic concentration in nutrient solution (table 2). Particularly, the plant biomass of leaves, stems, and roots of tobacco seedlings were significantly decreased $25.6 \%, 12.7 \%$, $28.0 \%$ by $100 \mathrm{mg} / \mathrm{L}$ CIP, and $11.6 \%, 10.3 \%, 9.2 \%$ by $100 \mathrm{mg} / \mathrm{L}$ NOR orderly. It suggested that the plant biomass especially the leaves biomass of tobacco seedlings were declined by increased antibiotic levels, with higher rate decreased by CIP than NOR.

Table 1. Growth traits of tobacco seedlings after 50 days treated with CIP and NOR levels.

\begin{tabular}{|c|c|c|c|c|c|c|}
\hline Treatment & $\begin{array}{l}\mathrm{mg} / \\
\mathrm{L}\end{array}$ & 0 & 25 & 50 & 75 & 100 \\
\hline \multirow{2}{*}{$\begin{array}{l}\text { Plant } \\
\text { height } \\
(\mathrm{cm})\end{array}$} & CIP & $\begin{array}{l}12.6 \\
7 \mathrm{a}\end{array}$ & $\begin{array}{l}12.17 \\
\mathrm{ab}\end{array}$ & $\begin{array}{l}11.56 \\
b c\end{array}$ & $\begin{array}{l}11.33 \\
b c\end{array}$ & $\begin{array}{l}10.5 \\
3 \mathrm{c}\end{array}$ \\
\hline & $\begin{array}{l}\mathrm{NO} \\
\mathrm{R}\end{array}$ & $\begin{array}{l}13.3 \\
0 \mathrm{a}\end{array}$ & $\begin{array}{l}12.40 \\
\mathrm{~b}\end{array}$ & $\begin{array}{l}12.10 \\
b\end{array}$ & $\begin{array}{l}11.80 \\
\text { b }\end{array}$ & $\begin{array}{l}11.8 \\
0 \mathrm{~b}\end{array}$ \\
\hline \multirow{2}{*}{$\begin{array}{l}\text { Stem } \\
\text { circumfer } \\
\text { ence }(\mathrm{cm})\end{array}$} & CIP & $\begin{array}{l}2.13 \\
\mathrm{a}\end{array}$ & $\begin{array}{l}2.07 \mathrm{a} \\
\mathrm{b}\end{array}$ & $\begin{array}{l}2.04 a \\
b\end{array}$ & $\begin{array}{l}2.03 a \\
b\end{array}$ & $\begin{array}{l}1.97 \\
b\end{array}$ \\
\hline & $\begin{array}{l}\mathrm{NO} \\
\mathrm{R}\end{array}$ & $\begin{array}{l}1.98 \\
\mathrm{a}\end{array}$ & $\begin{array}{l}1.88 \mathrm{a} \\
\mathrm{b}\end{array}$ & $\begin{array}{l}1.86 \mathrm{a} \\
\mathrm{b}\end{array}$ & $1.80 \mathrm{~b}$ & $\begin{array}{l}1.78 \\
\mathrm{~b}\end{array}$ \\
\hline \multirow{2}{*}{$\begin{array}{l}\text { Maximum } \\
\text { leaf } \\
\text { length } \\
(\mathrm{cm})\end{array}$} & CIP & $\begin{array}{l}12.1 \\
0 \mathrm{a} \\
\end{array}$ & $\begin{array}{l}12.02 \\
\mathrm{a}\end{array}$ & $\begin{array}{l}11.97 \\
\mathrm{a}\end{array}$ & $\begin{array}{l}11.83 \\
\mathrm{a}\end{array}$ & $\begin{array}{l}11.7 \\
3 \mathrm{a}\end{array}$ \\
\hline & $\begin{array}{l}\mathrm{NO} \\
\mathrm{R}\end{array}$ & $\begin{array}{l}13.1 \\
0 \mathrm{a}\end{array}$ & $\begin{array}{l}12.90 \\
\mathrm{a}\end{array}$ & $\begin{array}{l}12.60 \\
\mathrm{a}\end{array}$ & $\begin{array}{l}12.40 \\
\mathrm{a}\end{array}$ & $\begin{array}{l}12.3 \\
0 \mathrm{a}\end{array}$ \\
\hline \multirow{2}{*}{$\begin{array}{l}\text { Maximum } \\
\text { leaf width } \\
(\mathrm{cm})\end{array}$} & CIP & $\begin{array}{l}8.00 \\
\mathrm{a}\end{array}$ & $\begin{array}{l}7.83 a \\
b\end{array}$ & $\begin{array}{l}7.67 b \\
c\end{array}$ & $\begin{array}{l}7.54 \mathrm{~b} \\
\mathrm{c}\end{array}$ & $\begin{array}{l}7.17 \\
\mathrm{c}\end{array}$ \\
\hline & $\begin{array}{l}\mathrm{NO} \\
\mathrm{R}\end{array}$ & $\begin{array}{l}8.70 \\
a\end{array}$ & $8.60 \mathrm{a}$ & $8.60 \mathrm{a}$ & $7.90 \mathrm{~b}$ & $\begin{array}{l}7.60 \\
b\end{array}$ \\
\hline \multirow{2}{*}{$\begin{array}{l}\text { Maximum } \\
\text { leaf area } \\
(\mathrm{cm} 2)\end{array}$} & CIP & $\begin{array}{l}61.4 \\
2 \mathrm{a}\end{array}$ & $\begin{array}{l}59.71 \\
\text { b }\end{array}$ & $\begin{array}{l}58.25 \\
\mathrm{c}\end{array}$ & $\begin{array}{l}56.60 \\
\mathrm{~d}\end{array}$ & $\begin{array}{l}53.3 \\
6 \mathrm{e} \\
\end{array}$ \\
\hline & $\begin{array}{l}\mathrm{NO} \\
\mathrm{R}\end{array}$ & $\begin{array}{l}71.2 \\
1 \mathrm{a}\end{array}$ & $\begin{array}{l}67.95 \\
\text { b }\end{array}$ & $\begin{array}{l}67.66 \\
\mathrm{c}\end{array}$ & $\begin{array}{l}65.66 \\
d\end{array}$ & $\begin{array}{l}59.3 \\
1 \mathrm{e}\end{array}$ \\
\hline
\end{tabular}

Note: different letters in the same column of data represent significant differences $(P<0.05)$.

Table 2. Plant biomass (FW, g/plant) of tobacco seedlings leaves, stems, and roots after 50 days treated with different CIP and NOR levels

\begin{tabular}{|l|l|l|l|l|l|l|}
\hline $\begin{array}{c}\text { Treat } \\
\text { ment }\end{array}$ & $\mathrm{mg} / \mathrm{L}$ & 0 & 25 & 50 & 75 & 100 \\
\hline \multirow{4}{*}{$\mathrm{CIP}$} & Leaves & $6.53 \mathrm{a}$ & $6.27 \mathrm{a}$ & $5.94 \mathrm{~b}$ & $5.72 \mathrm{~b}$ & $5.60 \mathrm{c}$ \\
\cline { 2 - 7 } & stems & $2.75 \mathrm{a}$ & $2.66 \mathrm{a}$ & $2.49 \mathrm{~b}$ & $2.47 \mathrm{~b}$ & $2.40 \mathrm{~b}$ \\
\cline { 2 - 7 } & roots & $0.72 \mathrm{a}$ & $0.68 \mathrm{~b}$ & $0.68 \mathrm{~b}$ & $0.63 \mathrm{c}$ & $0.59 \mathrm{~d}$ \\
\hline \multirow{4}{*}{ NOR } & Leaves & $7.38 \mathrm{a}$ & $6.92 \mathrm{~b}$ & $6.94 \mathrm{~b}$ & $6.68 \mathrm{~b}$ & $6.52 \mathrm{c}$ \\
\cline { 2 - 7 } & stems & $2.91 \mathrm{a}$ & $2.84 \mathrm{a}$ & $2.69 \mathrm{~b}$ & $2.62 \mathrm{~b}$ & $2.61 \mathrm{~b}$ \\
\cline { 2 - 7 } & roots & $0.87 \mathrm{a}$ & $0.83 \mathrm{a}$ & $0.78 \mathrm{~b}$ & $0.83 \mathrm{a}$ & $0.79 \mathrm{~b}$ \\
\hline
\end{tabular}

Note: different letters in the same column of data represent significant differences $(P<0.05)$

\subsection{Responses of ciprofloxacin and norfloxacin concentrations in tobacco seedlings to different levels of ciprofloxacin and norfloxacin}

Contents of CIP and NOR in tobacco seedlings leaves all increased continuously with increasing antibiotic 
concentration in nutrient solution and time (table 3). At 30, 40, and 50 days Contents of CIP increased in the leaves of tobacco seedlings $85 \%, 99.1 \%, 115.9 \%$ by $100 \mathrm{mg} / \mathrm{L} \mathrm{CIP}$, the CIP contents of the T1, T2, T3, and T4 groups of tobacco seedlings at 50 days of treatment increased by $42 \%, 48 \%, 51 \%$, and $36 \%$. Contents of NOR increased in the leaves of tobacco seedlings $84 \%$, $95.7 \%, 115.6 \%$ by $100 \mathrm{mg} / \mathrm{L}$ NOR, the NOR contents of the T1, T2, T3, and T4 groups of tobacco seedlings at 50 days of treatment increased by $39 \%, 42 \%, 36 \%$, and $38 \%$. It indicated that the quinolone antibiotics treated with different concentrations did not disappear in tobacco seedlings and the content increased with time.

Table 3. CIP and NOR contents in tobacco seedlings (ug/g FW) treated with different CIP and NOR levels

\begin{tabular}{|l|l|l|l|l|l|l|}
\hline $\begin{array}{l}\text { Antibi } \\
\text { otic }\end{array}$ & $\begin{array}{l}\text { Treat } \\
\text { ment } \\
\text { days }\end{array}$ & 0 & 25 & 50 & 75 & 100 \\
\hline \multirow{4}{*}{ CIP } & 30 & 0 & $72.4 \mathrm{c}$ & $77.2 \mathrm{c}$ & $80.8 \mathrm{c}$ & $85.0 \mathrm{c}$ \\
\cline { 2 - 7 } & 40 & 0 & $96.7 \mathrm{~b}$ & $\begin{array}{l}106.3 \\
\mathrm{~b}\end{array}$ & $97.0 \mathrm{~b}$ & $99.1 \mathrm{~b}$ \\
\cline { 2 - 7 } & 50 & 0 & $\begin{array}{l}102.6 \\
\mathrm{a}\end{array}$ & $\begin{array}{l}113.9 \\
\mathrm{a}\end{array}$ & $\begin{array}{l}121.7 \\
\mathrm{a}\end{array}$ & $\begin{array}{l}115.9 \\
\mathrm{a}\end{array}$ \\
\hline \multirow{3}{*}{ NOR } & 30 & 0 & $64.3 \mathrm{c}$ & $66.2 \mathrm{c}$ & $77.4 \mathrm{c}$ & $84.0 \mathrm{c}$ \\
\cline { 2 - 7 } & 40 & 0 & $72.1 \mathrm{~b}$ & $76.0 \mathrm{~b}$ & $89.1 \mathrm{~b}$ & $95.7 \mathrm{~b}$ \\
\cline { 2 - 7 } & 50 & 0 & $89.3 \mathrm{a}$ & $93.8 \mathrm{a}$ & $\begin{array}{l}104.9 \\
\mathrm{a}\end{array}$ & $\begin{array}{l}115.6 \\
\mathrm{a}\end{array}$ \\
\hline
\end{tabular}

Note: different letters in the same column of data represent significant differences $(P<0.05)$.

\subsection{Responses of ciprofloxacin and norfloxacin accumulation in tobacco seedlings to different levels of ciprofloxacin and norfloxacin}

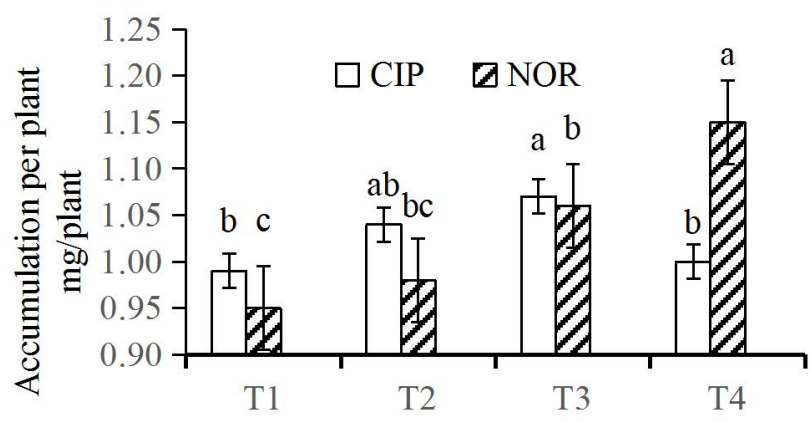

Figure 1. Antibiotic accumulation of tobacco seedlings after 50 days treated with CIP and NOR levels.

After 50 days, accumulation of CIP in tobacco seedlings reached the maximum in the $\mathrm{T} 3$ treatment group and accumulation of NOR in tobacco seedlings leaves increased continuously with increasing antibiotic concentration in nutrient solution (figure 1). Accumulation of CIP in the tobacco seedlings in the T3 was 1.1 times that of the tobacco seedlings in the $\mathrm{T} 1$, accumulation of NOR in the tobacco seedlings in the T4 was 1.2 times that of the tobacco seedlings in the $\mathrm{T} 1$. When the CIP concentration in the nutrient solution reached a certain value, the cumulative amount of CIP in the tobacco seedlings reached a maximum.

\section{Conclusion}

With the increase of quinolone antibiotic concentration, the growth of tobacco seedlings was inhibited with the increase of treatment concentration. This is consistent with the results of a previous study, which found that the growth of corn seedlings was inhibited when the concentration of norfloxacin exceeded $1 \mathrm{~mL} / \mathrm{L}$. [12] It was also found that the maximum leaf area of the tobacco seedlings was significantly inhibited, which is consistent with the results of a study by Qin et al. on the effects of ciprofloxacin on the agronomic traits of corn. [13] From the above we know that antibiotics can not only be absorbed and accumulated in plants, but also enter the human body through food, It brings potential risks to human health and ecological environment. With the increase of the concentration of two quinolones, the agronomic characters of tobacco seedlings became worse, plant height and biomass decreased, but the content and accumulation of antibiotics increased. So the hypothesis, quinolone antibiotics may affect the root activity of tobacco seedlings or the enzyme activity and chlorophyll in the body, so they have an inhibitory effect on the growth of tobacco seedlings, the future research direction can be extend from the biochemical direction of tobacco seedlings.

\section{References}

[1] Hongyan Li, Xinghan Chen. The current situation and hazards of antibiotic pollution in the environment [J]. Chin. Resour. Compr. Util., 2018, (5):82-95

[2] Weicheng Zhou. Progress in Research on Fluoroquinolone Antibacterials [J]. Chin. J. Pharm., 1997, 28 (2): 75-81.

[3] Yongbo Sun. Establishment and cumulative distribution of two methods of antibiotic analysis for quinolones in flue-cured tobacco seedlings [D]. Yunnan Agricultural University, 2017.

[4] Xiaojie Duan. Migration and accumulation of quinolones in vegetables [D]. Anhui Agricultural University, 2012.

[5] Xiaolian Wu, Cehui Mo, Qingyun Yan, Yuanneng Jiang, Lei Xiang, Yanwen Li, Xianpei Huang, Qingyun Su, Jiyang Wang. Content levels and health risk of quinolone antibiotics from vegetables of Dongguan farms [J]. Chin. Environ. Sci., 2013, 33 (5): 910-916.

[6] Yang Li, Yuxi Feng, Hua Zhang, Xiaozhang Yu. Estimating the synergistic and antagonistic effects of dual antibiotics on plants through root elongation test [J]. Ecotoxicol., 2020. https://doi.org/10.1007/ s10646-020-02308-y

[7] Caruso Rosalie V, O'Connor Richard J, Stephens W Edryd, Cummings K Michael, Fong Geoffrey T. 
Toxic Metal Concentrations in Cigarettes Obtained from U.S. Smokers in 2009: Results from the International Tobacco Control (ITC) United States Survey Cohort [J]. Int. J. Environ. Res. Public Health. 2014, 11 (1): 202-217. https://doi.org/ 10.3390/ijerph110100202

[8] Sveta Thakur, Lakhveer Singh, Zularisam Ab Wahid, Muhammad Faisal Siddiqui, Samson Mekbib Atnaw, Mohd Fadhil Md Din. Plant-driven removal of heavy metals from soil: uptake, translocation, tolerance mechanism, challenges, and future perspectives[J]. Environ. Monitor. Assess.. 2016, $\quad \mathbf{1 8 8} \quad$ (4): $1-11$. https://doi.org/10.1007/s10661-016-5211-9

[9] Yuan He, Haiwei Liu, Qi Shi, et al. Effects of Cadmium on the Growth of Tobacco and the Characteristics of Cadmium Accumulation by Tobacco [J]. Chin. Tob. Sci., 2015, 36 (2): 99-104.

[10] Fuzhao Nian, Yongbo Sun, and Yong Gu. Determination of oxytetracycline in tobacco seedlings $[\mathrm{P}]$. Yunnan Agricultural University, 2019.

[11] YCT142-2010 Investigation and measurement methods of tobacco agronomic traits [S]. Tobacco industry standard of the people's Republic of China. 2010.

[12] Peng Wang, Bei Liu, Shuzhen Zhang. Phytotoxicity and Oxidative Stress of Norfloxacin on Maize (Zea mays L.) Germination Stage [J]. Asia J. Ecotoxicol., 2010, 5 (6): 849-856.

[13] Junmei Qin, HuaYe Xiong. Effects of ciprofloxacin on maize growth and accumulation and residue characteristics of ciprofloxacin [J]. J. SXAU (Nat. Sci. Ed.)2017, 37 (2): 77-82. 